\title{
The importance of chronic pain education and awareness amongst occupational safety and health professionals
}

This article was published in the following Dove Press journal:

Journal of Pain Research

\author{
Chúk Odenigbo' \\ Nancy Julien ${ }^{2}$ \\ Nabiha Benyamina Douma ${ }^{2}$ \\ Anaïs Lacasse ${ }^{2}$ \\ 'Department of Environmental and \\ Occupational Health, School of Public \\ Health, Montreal University, Montreal, \\ Quebec, Canada; ${ }^{2}$ Department of Health \\ Sciences, University of Quebec in Abitibi- \\ Temiscamingue, Rouyn- \\ Noranda, Quebec, Canada
}

Correspondence: Anaïs Lacasse Département des sciences de la santé, Université du Québec en Abitibi-

Témiscamingue, 445, boul. de l'Université, Rouyn-Noranda, QC J9X 5E4, Canada

Tel + I8 I97620 97| 2722

Email lacassea@uqat.ca
Purpose: Occupational safety and health $(\mathrm{OSH})$ professionals are often the point of contact for health and safety policies derived in the workplace, and the handling of incidents in their aftermath. As chronic pain affects $20 \%$ of people, many pain-awareness campaigns and educational activities target healthcare professionals. However, initiatives directed toward OSH professionals are also important to aid in prevention and rehabilitation efforts. The objective of this study was to describe knowledge and attitudes of OSH students with regard to chronic pain.

Methods: A web-based cross-sectional study was conducted amongst a convenience sample of 88 students enrolled in the distance learning OSH undergraduate certificate program at the Université du Québec en Abitibi-Témiscamingue (Quebec, Canada).

Results: Although $30 \%$ of students were already employed within OSH or human resources and $40 \%$ reported intervening in cases involving chronic pain in their line of work, $56 \%$ of respondents had received no training on chronic pain and its treatment in the past five years. Only $14 \%$ chose to take the optional $45 \mathrm{hr}$ course dedicated to pain within the program. OSH students also exhibited poorer knowledge and more negative attitudes toward people suffering from chronic pain when compared to other groups assessed in the province of Quebec, including healthcare professionals, chronic pain patients, and people not suffering from chronic pain $(p \leq 0.0002)$. Half of the respondents $(51.9 \%)$ were not aware that chronic pain affects 1 in 5 adults.

Conclusion: Our study demonstrates a need for pain education within OSH training programs and through continuing education.

Keywords: knowledge, attitudes, education, chronic pain, occupational safety and health, $\mathrm{OSH}$

\section{Introduction}

Occupational safety and health (OSH) can be defined as the "science of the anticipation, recognition, evaluation and control of hazards arising in or from the workplace that could impair the health and well-being of workers, taking into account the possible impact on the surrounding communities and the general environment". 'According to the Institute of Medicine (US), OSH professionals, who may come from various fields such as occupational safety, industrial hygiene, occupational medicine, and occupational health nursing, "share the common goal of identifying hazardous conditions, materials, and practices in the workplace and assisting employers and workers in eliminating or reducing the attendant risks." 2 In Canada, the Board of Canadian 
Registered Safety Professionals defines OSH professionals achieving certification as individuals applying broad based safety knowledge to analyze and develop systems that will achieve optimum control over hazards and exposures detrimental to people, equipment, material and the environment. [...] dedicated to the principles of loss control, incident prevention and environmental protection as demonstrated by their daily activities. ${ }^{3}$

Amongst the many issues that OSH professionals are to consider is the effect of new or existing health problems in the paradigm of one's professional duties. Chronic pain, for example, is a common health concern faced by an estimated $20 \%$ of the adult population worldwide. ${ }^{4}$ It is often misunderstood in clinical practice and amongst the general public. ${ }^{5}$ Defined as persisting for over three to six months, chronic pain impacts all aspects of daily life for those who suffer from it, including workplace absenteeism and presenteeism. ${ }^{4,6}$ Even when one considers the higherend estimates, chronic pain is believed to be underreported, under-diagnosed and under-recognized..$^{7-12}$ Unfortunately, there tends to be stigmatization and lack of empathy toward chronic pain sufferers. Such stigmatization is observed not only amongst the general public, but amongst healthcare professionals as well. ${ }^{13-15}$ In addition to the enormous personal consequences it entails, chronic pain is also an economic burden to our society, including insurers and employers. ${ }^{16-18}$

In the workplace specifically, the negative impact of chronic pain on workers, employers and society as a whole has been examined. For example, a large portion of police officers in Quebec report a reduction of work activities (64.4\%) and an increased use of health services due to chronic low back pain. ${ }^{19}$ Furthermore, some US-specific reports showed 323 billion USD in annual losses by the government, taxpayers and employers due to prescription costs, missed work days, lower wages and reduced productivity due to chronic pain. ${ }^{20}$ European data also outline employment rates falling from $81 \%$ (people without chronic pain) to $24 \%$ for those suffering from severe chronic pain. ${ }^{21}$ Moreover, those in the workplace are at greater risk for developing chronic pain-over one quarter of all low back pain-related disability cases are directly linked to occupational issues. ${ }^{22}$

Given that chronic pain is a biopsychosocial chronic condition, a heightened sense of awareness, better education and increased sensitivity are all needed to better integrate the afflicted into society. ${ }^{23}$ Extensive research has been conducted on pain education needs amongst healthcare professionals (nurses, physicians, pharmacists, physiotherapists, etc.). ${ }^{24-27}$ Suggestions include improving understanding through various means, for example, incorporating pain education into nursing pre-licensure training. ${ }^{28}$ However, people in critical positions in public spheres, such as OSH professionals, have been unwittingly skipped. As shown in literature, ${ }^{29}$ given the direction in which OSH is headed, the future of this sector lies in the governance and handling of chronic noncommunicable diseases.

By targeting health experts stationed in occupational settings, efforts can be made to both improve mitigation and rehabilitation as it stands. OSH professionals are often called upon to advise and support workers suffering from chronic pain. They are also required to survey working conditions that put workers at risk for developing chronic pain. ${ }^{30}$ Given their instrumental role, it is important to gain an understanding of their current knowledge and attitudes. Whether certified healthcare practitioners or not, OSH professionals should be able to understand pain. They should know how to prevent pain chronicization following an injury, and have the necessary knowledge to act in disability benefit cases, helping workers apply healthcare professional recommendations. Above all, they should act without prejudiced against people suffering from chronic pain.

As a starting point for understanding the awareness and educational needs amongst OSH professionals, the objective of this study was to provide an understanding of the knowledge and attitudes of OSH students with regard to chronic pain. There are currently no published studies that link OSH professionals to chronic pain.

\section{Methods}

\section{Study design and population}

During the winter semester of 2015 (between the months of January and April), a web-based crosssectional descriptive study was conducted amongst active students enrolled in the distance learning OSH undergraduate certificate program (Certificat en santé et sécurité au travail) at the Université du Québec en Abitibi-Témiscamingue (Rouyn-Noranda, Quebec, Canada). Approval was obtained from the Institutional Ethical Review Board (December 10, 2014) and all participants provided informed consent to participate. 
In the province of Quebec, there is no mandatory curricula, certification exam or board registration to be able to work in the field of OSH. Nonetheless, the OSH certificate program offers students the opportunity to improve and build upon their competencies and skills through academic training serving to establish a solid foundation in occupational health. This program also encourages the development of preventative measures while focusing on incorporating critical abilities such as leadership and project management. This program is geared toward those who express an interest in becoming OSH professionals, regardless of industry. Available through distance learning, the program allows students to adapt their study schedule to their lives, thereby augmenting the diversity of people enrolled. Geography does not stand as a barrier and students come from every corner of the province.

The result of the program's wide availability is a student population including active professionals various industries, individual already working in OSH but seeking further credentials, unemployed students working toward starting a career, and many other scenarios. Enrolled students also span a broad spectrum of positions, including managers, nurses, human resource agents and budding professionals.

\section{Data collection and variables}

The SurveyMonkey Gold ${ }^{\circledR}$ (San Mateo, CA: SurveyMonkey Inc.) software was used to launch the study questionnaire online and collect data. An email invitation to complete the questionnaire was sent to all students actively enrolled in the OSH certificate program. The email invitation contained the survey hyperlink redirecting potential participants to an online introduction page providing enough information to insure informed consent. Only participants who checked "I consent to participate in this study" were redirected to the survey.

The questionnaire focused on whether or not participants had ever intervened in pain cases, past pain education, self-perceived pain knowledge, and the level of comfort in responding to pain cases. Perceptions toward people suffering from chronic pain were measured using the validated Chronic Pain Myth Scale (CPMS). ${ }^{31}$ The CPMS is composed of three subscales: (1) the assessment of knowledge, beliefs and attitudes toward chronic pain sufferers; (2) toward the biopsychosocial impacts of chronic pain; and (3) toward treatment practices. The CPMS was designed and validated as a generic one-size- fits-all measure that can be used in various populations, such as healthcare professionals and the general public. The twenty-six multiple choice questions of the CPMS are answered using Likert scales ranging from 1 (Completely disagree) to 5 (Completely agree), and allow the calculation of three subscale scores by adding the responses (higher scores indicate better knowledge and more positive beliefs and attitudes). For the purposes of this study, only the first subscale of the CPMS was considered (knowledge, beliefs and attitudes toward chronic pain sufferers; 9 items; scores range from 9 to 45). Included in the survey were also questions on the respondent's age, sex, level of education, their chronic pain status and that of their close relatives, employment, professional duties that relate to OSH policy, and whether or not they had opted to take an elective $45 \mathrm{hr}$ course offered on pain as part of their certificate (SCL1416 Phénomène de la douleur). Such de novo questions were reviewed by pain experts for relevance and accuracy, and pre-tested to ensure that the questions were easily comprehensible.

\section{Statistical analysis}

Data related to the characteristics, knowledge and beliefs of the study population was converted into means, standard deviations (SDs) and frequency tables ( $\mathrm{n}$ and \%). CPMS scores were compared to published data about the Quebec population ${ }^{31}$ using one sample t-tests. Bivariate comparisons of scores between men and women, and between students that were already employed within OSH or human resources and students that were not, were performed using independent group t-tests. All analyses were conducted with SPSS Statistics ${ }^{\circledR}$ version 22 (Armonk, NY: IBM Corp) and SAS ${ }^{\circledR}$ version 9.4 (Cary, NC: SAS Institute).

\section{Results}

Eighty-eight responses were received from active students enrolled in the OSH certificate program. Thirteen out of the seventeen administrative regions of the province of Quebec were represented. According to statistical data from the Registrar's Office, the participation rate was $30.4 \%(88 / 289)$.

The characteristics of our study sample are shown in Table 1. More women responded than men, the former representing $69 \%$ of the sample. Three quarters of respondents were currently employed on a full-time basis. Just under $30 \%$ were already employed within OSH or human resources. Furthermore, $46 \%$ reported 
Table I Study population's characteristics

\begin{tabular}{|c|c|c|}
\hline \multirow{2}{*}{$\begin{array}{l}\text { Characteristics } \mathbf{n}=\mathbf{8 8} \\
\text { Age }(\text { years })^{\mathrm{b}}-\text { mean } \pm S D\end{array}$} & \multicolumn{2}{|c|}{ No. (\%) of participants ${ }^{2}$} \\
\hline & 33.7 & \pm 7.5 \\
\hline \multicolumn{3}{|l|}{ Sex ${ }^{c}$} \\
\hline Females & 49 & $(69.0)$ \\
\hline Males & 22 & $(31.0)$ \\
\hline \multicolumn{3}{|l|}{ Completed education level $^{c}$} \\
\hline College/CÉGEP & 36 & $(53.7)$ \\
\hline University - Undergraduate studies & 28 & $(4 I .8)$ \\
\hline University - Graduate studies & 3 & $(4.5)$ \\
\hline \multicolumn{3}{|c|}{ Suffering from chronic pain (pain for $\geq 3$ months) ${ }^{c}$} \\
\hline Yes & 12 & $(16.7)$ \\
\hline No & 60 & $(83.3)$ \\
\hline \multicolumn{3}{|c|}{ Knowing a close relative who suffers from chronic pain ${ }^{c}$} \\
\hline Yes & 33 & $(45.8)$ \\
\hline No & 39 & $(54.2)$ \\
\hline \multicolumn{3}{|l|}{ Employment status $^{c}$} \\
\hline Full-time job & 54 & $(75.0)$ \\
\hline Part-time job ( $\leq 20$ hrs per week) & 11 & $(15.3)$ \\
\hline Unemployed & 7 & $(9.7)$ \\
\hline \multicolumn{3}{|c|}{ Already employed within OSH or human resources ${ }^{d}$} \\
\hline Yes & 26 & $(29.9)$ \\
\hline No & 61 & $(70.1)$ \\
\hline \multicolumn{3}{|c|}{ Completed the optional 45 hour course dedicated to pain before completing our survey ${ }^{d}$} \\
\hline Yes & 12 & $(13.6)$ \\
\hline No & 76 & $(86.4)$ \\
\hline
\end{tabular}

Notes: ${ }^{a}$ Unless stated otherwise. ${ }^{b}$ Proportion of missing data $=42.0 \%$. ${ }^{\mathrm{c} P r o p o r t i o n}$ of missing data between $18.2 \%$ and $23.9 \%$. ${ }^{\mathrm{d}}$ Proportion of missing data $\leq 2 \%$ Abbreviations: OSH, Occupational Safety and Health; SD, Standard Deviation.

having a close friend or family member suffering from chronic pain. Only $13.6 \%$ had completed the optional pain course as part of their program (SCL1416 Phénomène de la douleur).

\section{Knowledge and attitudes toward pain}

As shown in Figure 1, a substantial portion of respondents reported intervening in cases involving acute $(46.6 \%)$ or chronic pain $(40.2 \%)$ in their line of work. However, over fifty percent of OSH students provided the four following answers: (1) not aware that chronic pain affects 1 in 5 people $(51.9 \%)$; (2) have received no education on chronic pain and treatment in the past five years (56.4\%); (3) have low self-perceived knowledge on the matter $(\leq 5 / 10$ score: $56.1 \%)$; (4) are uncomfortable with having to intervene with people suffering from chronic pain ( $\leq 5 / 10$ comfort level score: $67.8 \%)$.
When compared to other targeted groups (Figure 2), ${ }^{31}$ the study population of this particular project (OSH students: $35.4 \pm 6.3$ ) exhibited lower scores of knowledge and attitudes toward people suffering from chronic (one sample t-tests were conducted using published scores of knowledge and attitudes amongst Healthcare professionals: $39.9 \pm 4.1 / /$ Chronic pain patients: 40.6 \pm 4.0 // People of the general population not suffering from chronic pain: $38.4 \pm 4.7)$. All differences appear to be statistically ( $p$-values $\leq 0.0002$ ) and clinically significant (the minimally important change for this CPMS subscale is 1.9). In our sample, respondents already employed within OSH or human resources showed lower scores of knowledge and attitudes toward people suffering from chronic pain than those who were not yet working in the field (CPMS scores: $33.0 \pm 6.1$ vs $36.5 \pm 6.1$; independent group t-tests $p=0.0307)$. No difference was found between men 
Reported intervening in cases involving chronic pain

Reported intervening in cases involving acute pain

Were not aware that chronic pain affects approximately 1 in 5 adults

Reported zero hours of education about pain and its treatment in the past 5 years

Rated the sufficiency of their pain knowledge $\leq 5$ on a $0-10$ numerical scale $(0=$ very insufficient and $10=$ very sufficient $)$

Rated their level of comfort to intervene with people suffering from chronic pain $\leq 5$ on a $0-10$ numerical scale $(0=$ very uncomfortable and $10=$ very comfortable)

Rated their level of comfort to intervene with people suffering from acute pain $\leq 5$ on a $0-10$ numerical scale $(0=$ very uncomfortable and $10=$ very comfortable)

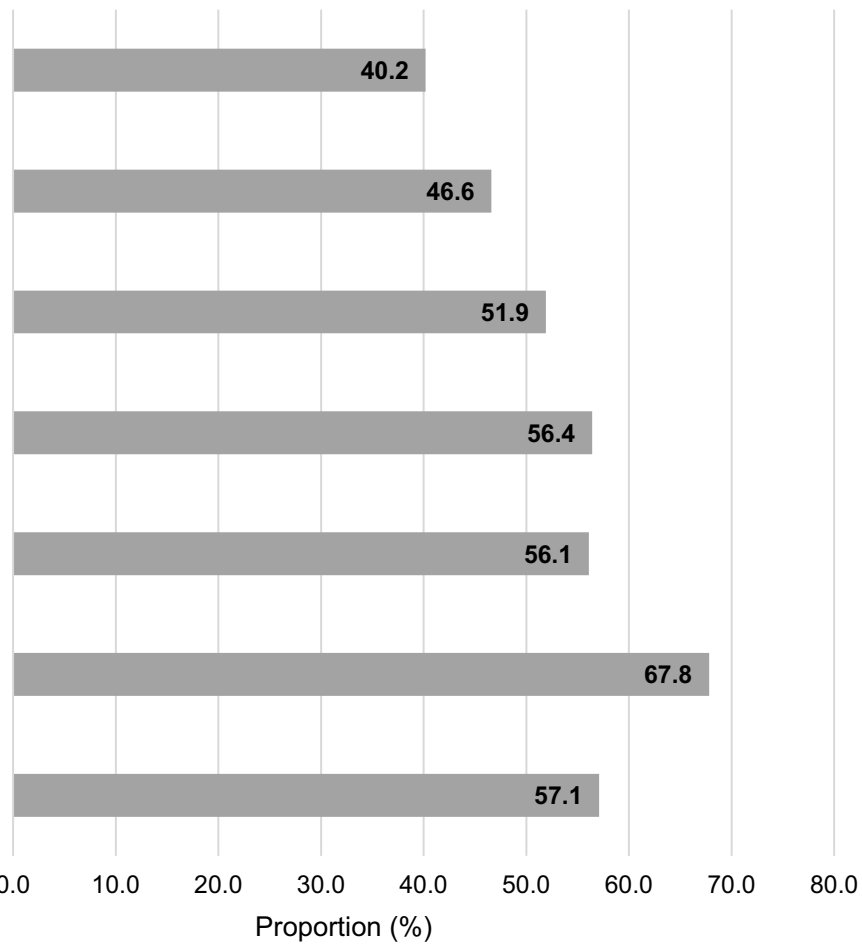

Figure I Knowledge, experience and comfort level of the study population with chronic pain.

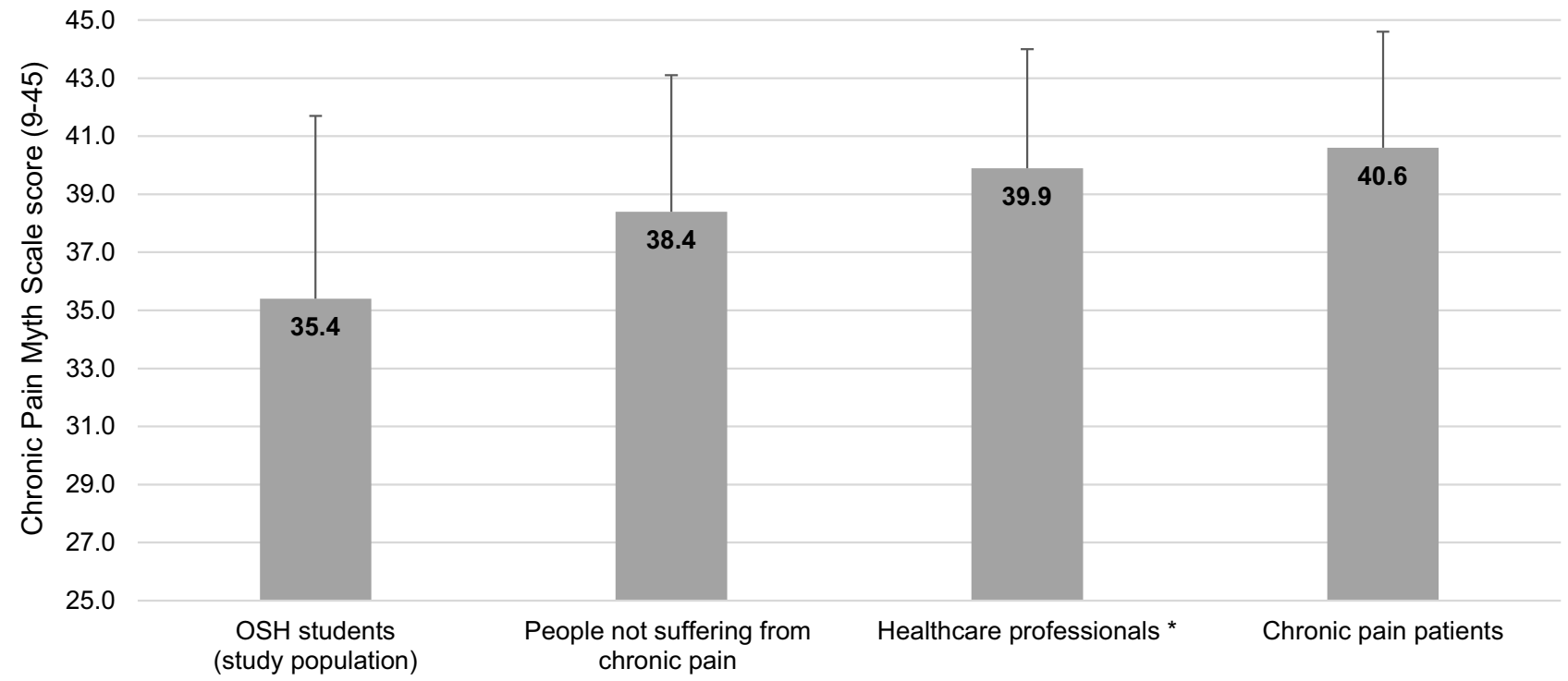

Figure 2 Knowledge and attitudes of various groups in the Province of Quebec using the Chronic Pain Myth Scale (CPMS). *Physician, nurse, physiotherapist, psychologist or pharmacist. One sample $t$-tests comparing scores among OSH students vs other groups: All $p \leq 0.0002$.

and women (CPMS scores: $34.5 \pm 6.2$ vs $35.9 \pm 6.4$; $p=0.4086$ ).

\section{Discussion}

This study presents a starting point for understanding the awareness and educational needs amongst OSH students and even individuals already employed within OSH or human resources. Although the sample size did not allow us to properly investigate predictors of knowledge and attitudes, it provides preliminary insight as to the importance of further pursuing this line of questioning in order to fully grasp the potential positive outcomes that could take place should targeted education and awareness programs be created for these professionals. 
The large majority of our study population were fulltime working women, with an estimated $30 \%$ already in OSH or human resource positions. In essence, they were a sample of the present and future OSH professionals that will be seen in the Quebec workforce in the upcoming years. Our study was able to gain both the perspective of those holding roles and duties relating to $\mathrm{OSH}$, as well as that of trainees. Our results suggest that pain education is not considered important, even though over $40 \%$ have been in situations requiring an understanding of pain. Potentially stemming from a lack of awareness, the reasons behind this are to be explored. Such work could lead to identifying the best methods to promote the importance of pain education and to provide access to such education amongst these professionals.

When compared to healthcare professionals, people suffering from chronic pain, and people who do not, the participants exhibited lower knowledge and held more negative attitudes toward chronic pain sufferers. While OSH professionals are not all primary providers of care such as physicians, nurses, or physiotherapists, they are the first point of contact in the workplace for prevention and for policies and operating procedures to ensure postaccident worker reintegration (a crucial period for preventing pain chronicization). Moreover, given the prevalence of chronic pain (an estimated 1 out of every 5 people being afflicted, ${ }^{4}$ it is especially important that chronic pain sufferers feel understood and supported in the workplace.

Studies show that chronic pain has a substantial negative impact on work performance. Between $13 \%$ and $76 \%$ of people across Europe were reported work-disabled because of chronic pain, ${ }^{21}$ this further highlights the obligation to find ways to manage pain in the workplace. Oswald et al (2015), were able to demonstrate a link between employee happiness and productivity, whereby happy employees perform on average $12 \%$ better than others. ${ }^{32}$ Chronic pain is not just a physical disability, it also affects the mental and emotional health of those afflicted. Treatment and workplace integration must therefore adopt a multi-pronged approach. OSH professionals are often in charge of developing appropriate policies and educating their co-workers on various aspects of health in the workplace. That said, in order for them to be successful, it is crucial that they master the more common chronic conditions and how best to manage them.

The vast majority of participants expressed significant levels of discomfort with regard to intervening in cases involving chronic or acute pain. However, the high prevalence of such a condition in the workplace makes such interventions unavoidable. ${ }^{33}$ A total of $46 \%$ of respondents mentioned having a friend or family member with chronic pain. This shows that familiarity with chronic pain sufferers is non-indicative of comfort in dealing with the condition. This study introduces a new avenue which may lead to new approaches and provide additional allies (OSH professionals) in the efforts to prevent post-accident pain chronicization and promote practices and behaviors that limit prejudices toward chronic pain sufferers in the workplace.

\section{Strengths and limitations}

The strengths of this study include the careful development and pretesting of the questionnaire and the minimization of errors in computerizing data through the use of a survey web platform. However, we cannot exclude the possibility of a social desirability bias in participants' responses, and our sample size did not allow the use of a multivariable analysis for the identification of the predictors of knowledge, beliefs and attitudes toward people suffering from chronic pain. A response rate of only $30 \%$ was reached which increases the chances of a section bias. However, we should mention that many student surveys report response rates below $20 \% .{ }^{34}$ As for external validity, this study questions whether or not it is necessary to educate OSH professionals on chronic pain through the evaluation of a sample of students enrolled in a certificate program. This program offers distance learning, thus enabling a wide geographic distribution of students. The province of Quebec is divided into seventeen administrative regions. Survey responses were obtained from thirteen of these regions (76.5\%). Although the study presents a diverse array of responses from a wide selection of people, it is limited in that it focuses on a subsection of the Canadian population holding unique $\mathrm{OSH}$ legislation that is not uniform across the country. The findings of this study cannot be extrapolated to all international settings.

\section{Conclusion}

Given the under-diagnosed and under-recognized status of chronic pain amongst trained healthcare professionals, and the prejudices held by the general public, the results of this study are not surprising. However, such data collected from OSH professionals and students is essential to reach and persuade decision makers (such as employers and training program managers) to invest time and resources 
in finding solutions that match educational needs. According to our study, pain education should become a mandatory requirement for $\mathrm{OSH}$ students to enable them to better handle their professional responsibilities, and continuing education in chronic pain should be made available for professionals already in the field. Future research should explore the biopsychosocial determinants of knowledge and attitudes amongst OSH professionals, the role of $\mathrm{OSH}$ professionals in chronic pain prevention and management, and the improvement of training programs.

\section{Acknowledgments}

We would like to thank the Registrar's Office and Information Technology Department of the Université du Québec en Abitibi-Témiscamingue for their help in the distribution of the survey invitations, and Ms Emily-Jayn Rubec who provided linguistic revision services.

\section{Disclosure}

This study was supported by the Fondation de l'Université du Québec en Abitibi-Témiscamingue (FUQAT). The authors report no further conflicts of interest in this work.

\section{References}

1. Alli BO. Fundamental Principles of Occupational Health and Safety. Geneva: International Labour Organization; 2008.

2. Institute of Medicine. Safe Work in the 21st Century: Education and Training Needs for the Next Decade's Occupational Safety and Health Personnel. Washington, DC: Institute of Medicine (US) Committee to Assess Training Needs for Occupational Safety and Health Personnel in the United States, National Academies Press (US); 2000

3. BCRSP. History of the BCRSP; 2016. Available from: https://www. bcrsp.ca/about-us. Accessed January 10, 2019.

4. Moore RA, Derry S, Taylor RS, Straube S, Phillips CJ. The costs and consequences of adequately managed chronic non-cancer pain and chronic neuropathic pain. Pain Pract. 2014;14(1):79-94. doi:10.1111/ papr. 12050

5. Lacasse A, Choiniere M, Connelly J-A. Knowledge, beliefs, and attitudes of the Quebec population toward chronic pain: where are we now? Can $J$ Pain. 2017;1(1):151-160. doi:10.1080/ 24740527.2017.1369849

6. Bouhassira D, Lanteri-Minet M, Attal N, Laurent B, Touboul C. Prevalence of chronic pain with neuropathic characteristics in the general population. Pain. 2008;136(3):380-387. doi:10.1016/j. pain.2007.08.013

7. Zuccaro SM, Vellucci R, Sarzi-Puttini P, Cherubino P, Labianca R, Fornasari D. Barriers to pain management: focus on opioid therapy. Clin Drug Investig. 2012;32(Suppl 1):11-19. doi:10.2165/11630040000000000-00000

8. MacDonald NE, Flegel K, Hebert PC, Stanbrook MB. Better management of chronic pain care for all. Cmaj. 2011;183(16):1815 doi:10.1503/cmaj. 111065
9. Kingma EM, Rosmalen JG. The power of longitudinal population-based studies for investigating the etiology of chronic widespread pain. Pain. 2012;153(12):2305-2306. doi:10.1016/j. pain.2012.09.001

10. Sessle BJ. The pain crisis: what it is and what can be done. Pain Res Treat. 2012;2012(703947):1-6. doi:10.1155/2012/703947

11. Lalonde L, Choiniere M, Martin E, et al. Priority interventions to improve the management of chronic non-cancer pain in primary care: a participatory research of the ACCORD program. J Pain Res. 2015;8:203-215. doi:10.2147/JPR.S78177

12. Kress HG, Aldington D, Alon E, et al. A holistic approach to chronic pain management that involves all stakeholders: change is needed. Curr Med Res Opin. 2015;31(9):1743-1754. doi:10.1185/ 03007995.2015.1072088

13. Cohen M, Quintner J, Buchanan D, Nielsen M, Guy L. Stigmatization of patients with chronic pain: the extinction of empathy. Pain Med. 2011;12(11):1637-1643. doi:10.1111/j.15264637.2011.01264.x

14. Newton BJ, Southall JL, Raphael JH, Ashford RL, LeMarchand K. A narrative review of the impact of disbelief in chronic pain. Pain Manag Nurs. 2013;14(3):161-171. doi:10.1016/j.pmn.2010.09.001

15. De Ruddere L, Craig KD. Understanding stigma and chronic pain: a-state-of-the-art review. Pain. 2016;157(8):1607-1610. doi:10.1097/ j.pain.0000000000000512

16. Kronborg C, Handberg G, Axelsen F. Health care costs, work productivity and activity impairment in non-malignant chronic pain patients. Eur J Health Econ. 2009;10(1):5-13. doi:10.1007/s10198-008-0096-3

17. Guerriere DN, Choiniere M, Dion D, et al. The Canadian STOP-PAIN project - part 2: what is the cost of pain for patients on waitlists of multidisciplinary pain treatment facilities? Can $J$ Anaesth. 2010;57(6):549-558. doi:10.1007/s12630-0109306-4

18. Lalonde L, Choiniere M, Martin E, Berbiche D, Perreault S, Lussier D. Costs of moderate to severe chronic pain in primary care patients - a study of the ACCORD program. $J$ Pain Res. 2014:7:389-403. doi:10.2147/JPR.S55388

19. Benyamina Douma N, Cote C, Lacasse A. Quebec serve and protect low back pain study: a web-based cross-sectional investigation of prevalence and functional impact among police officers. Spine (Phila Pa 1976). 2017;42(19):1485-1493. doi:10.1097/BRS.0000000000002136

20. Institute of Medicine. Relieving Pain in America: A Blueprint for Transforming Prevention, Care, Education, and Research. Washington D.C.: National Academies Press; 2011.

21. Patel AS, Farquharson R, Carroll D, et al. The impact and burden of chronic pain in the workplace: a qualitative systematic review. Pain Pract. 2012;12(7):578-589. doi:10.1111/j.1533-2500.2012. 00547.x

22. Driscoll T, Jacklyn G, Orchard J, et al. The global burden of occupationally related low back pain: estimates from the global burden of disease 2010 study. Ann Rheum Dis. 2014;73(6):975-981. doi:10.1136/annrheumdis-2013-204631

23. Walker S, Bablis P, Pollard H, McHardy A. Practitioner perceptions of emotions associated with pain: a survey. J Chiropr Med. 2005;4 (1):11-18. doi:10.1016/S0899-3467(07)60107-4

24. Chow KM, Chan JCY. Pain knowledge and attitudes of nursing students: a literature review. Nurse Educ Today. 2015;35 (2):366-372. doi:10.1016/j.nedt.2014.10.019

25. Lalonde L, Leroux-Lapointe V, Choiniere M, et al. Knowledge, attitudes and beliefs about chronic noncancer pain in primary care: a Canadian survey of physicians and pharmacists. Pain Res Manag. 2014;19(5):241-250.

26. Simmonds MJ, Derghazarian T, Vlaeyen JWS. Physiotherapists' knowledge, attitudes, and intolerance of uncertainty influence decision making in low back pain. Clin J Pain. 2012;28(6):467-474. doi:10.1097/AJP.0b013e31825bfe65 
27. Wenghofer EF, Wilson L, Kahan M, et al. Survey of Ontario primary care physicians' experiences with opioid prescribing. Can Fam Physician. 2011;57(3):324-332.

28. Herr K, Marie BS, Gordon DB, et al. An interprofessional consensus of core competencies for prelicensure education in pain management: curriculum application for nursing. J Nurs Educ. 2015;54(6):317-327. doi:10.3928/01484834-2015051502

29. Harrison J, Dawson L. Occupational health: meeting the challenges of the next 20 years. Saf Health Work. 2016;7(2):143-149. doi:10.1016/j.shaw.2015.12.004

30. Ratti N, Pilling K. Back pain in the workplace. Rheumatology. 1997;36(2):260-264. doi:10.1093/rheumatology/36.2.260
31. Lacasse A, Connelly JA, Choiniere M. The chronic pain myth scale: development and validation of a French-Canadian instrument measuring knowledge, beliefs, and attitudes of people in the community towards chronic pain. Pain Res Manage. 2016;2016:5940206. doi:10.1155/2016/ 5940206

32. Oswald AJ, Proto E, Sgroi D. Happiness and productivity. J Labor Econ. 2015;33(4):789-822. doi:10.1086/681096

33. Cassidy JD, Carroll LJ, Côté P. The Saskatchewan health and back pain survey. The prevalence of low back pain and related disability in Saskatchewan adults. Spine. 1998;23(17):1860-1866. discussion 1867.

34. Van Mol C. Improving web survey efficiency: the impact of an extra reminder and reminder content on web survey response. Int J Soc Res Methodol. 2017;20(4):317-327. doi:10.1080/13645579.2016.1185255

\section{Publish your work in this journal}

The Journal of Pain Research is an international, peer reviewed, open access, online journal that welcomes laboratory and clinical findings in the fields of pain research and the prevention and management of pain. Original research, reviews, symposium reports, hypothesis formation and commentaries are all considered for publication. The manuscript management system is completely online and includes a very quick and fair peer-review system, which is all easy to use. Visit http:// www.dovepress.com/testimonials.php to read real quotes from published authors. 